\title{
Addressing Opioid Misuse Among Veterans: A Peer-Delivered Opioid Prevention Curriculum
}

\section{Myah Pazdera}

Kajua B. Lor

Medical College of Wisconsin, USA

Otis Winstead Jr.

Dryhootch of America, Inc., USA

L. Kevin Hamberger

Medical College of Wisconsin, USA

\section{Bob Curry}

Dryhootch of America, Inc., USA

\section{Zeno Franco}

Sarah O'Connor

Medical College of Wisconsin, USA

Martina Gollin-Graves

Mental Health America of Wisconsin, USA

\section{Robert Hurley}

Wake Forest University, USA

Tiffiney Gray

Syed M. Ahmed

Medical College of Wisconsin, USA

\section{Recommended Citation}

Pazdera, M., Lor, K. B., Winstead Jr., O., Hamberger, L. K., Curry, B., Franco, Z., O'Connor, S., Gollin-Graves, M., Hurley, R., Gray, T., \& Ahmed, S. M. (2021). Addressing opioid misuse among veterans: A peerdelivered opioid prevention curriculum. International Journal of Research on Service-Learning and Community Engagement, 9(1). Article 7. https://doi.org/10.37333/001c.31319 


\section{Addressing Opioid Misuse Among Veterans: A Peer-Delivered Opioid Prevention Curriculum}

\author{
Myah Pazdera, Kajua B. Lor, Otis Winstead \\ Jr., L. Kevin Hamberger, Bob Curry, Zeno \\ Franco, Sarah O’Connor, Martina Gollin- \\ Graves, Robert Hurley, Tiffiney Gray, and \\ Syed M. Ahmed
}

Opioid use disorder (OUD) disproportionately affects military Veterans, who are more likely than the general population to experience chronic pain. A community-academic partnership launched a community-engaged research (CEnR) project designed to train Veteran peer mentor specialists to prevent and reduce opioid abuse among Veterans. A series of focus groups were conducted to obtain community input for the development of an opioid prevention curriculum to be utilized by peer mentor specialists. The focus group participants' experiences contributed to nuanced perspectives that fostered appreciation of knowledge and service gaps by using a CEnR approach. The themes that emerged informed a curriculum with key concepts related to opioid abuse and recovery for peer mentor specialists providing peer support for Veterans. Integrating research with community input and partnerships optimizes the opportunity to address aspects of OUD experienced by Veterans and closes a significant gap in this area of study and practice.

Keywords: community-engaged research, opioid use disorder (OUD), peer mentor specialist, Veterans

\section{Aproximación al abuso de opiáceos entre veteranos: un currículo de prevención de opiáceos entre pares}

\author{
Myah Pazdera, Kajua B. Lor, Otis Winstead \\ Jr., L. Kevin Hamberger, Bob Curry, Zeno \\ Franco, Sarah O'Connor, Martina Gollin- \\ Graves, Robert Hurley, Tiffiney Gray, y \\ Syed M. Ahmed
}

El trastorno del uso de opiáceos (Opiate Use Disorder) afecta de manera desproporcionada a los militares veteranos, el grupo más propenso a experimentar dolor crónico. Una colaboración entre la comunidad y el ámbito académico resultó en un proyecto de investigación con vinculación comunitaria (Community-Engaged Research, CEnR) cuyo objetivo era el de entrenar a pares mentores para prevenir y reducir el abuso de opiáceos. Diversos grupos de trabajo recogieron percepciones y observaciones de la comunidad para el desarrollo de un currículo de prevención de consumo de opiáceos entre los veteranos que fuera usado por los pares mentores. Las experiencias de los participantes en los grupos de trabajo contribuyerorn a facilitar perspectivas más matizadas que facilitaron la identificación de carencias y diferentes aspectos a desarrollar. Los temas tratados informaron un currículo con términos clave relativos al abuso de opiáceos y a la recuperación para los pares mentores de los veteranos. La integración de la investigación y de la participación comunitaria posibilita un acercamiento a los diferentes aspectos del trastorno del uso de opiáceos desde la experiencia de los veteranos y aborda una área de estudio y práctica poco explorada.

Palabras clave: investigación con vinculación comunitaria (CEnR), trastorno de uso de opiáceos (OUD), par mentor, veteranos

Editors' Note: Translation by Maria Fernandez Cifuentes

Department of Languages, Literatures, and Cultures University of North Florida, USA 
National trends indicate an alarming increase in opioid overdoses (Mattson et al., 2021) and our community has seen a similar trend. In 2016, the rate of opioid overdose death in Milwaukee County, where the city of Milwaukee is located, was double the rate for the state of Wisconsin (Milwaukee Community Opioid Prevention Effort, 2019). Drug overdose is recognized as a leading cause of accidental death in the United States (Visconti et al., 2015). Opioids are medications that relieve pain by reducing the intensity of pain signals reaching the brain and affect the brain areas governing emotion (U.S. Department of Veterans Affairs, 2018). Patients with chronic non-cancer-related pain who took opioids for more than 90 days, even at low doses, had substantially higher odds of developing opioid use disorder (OUD) (Schuchat et al., 2017). Taking opioids for an extended period of time increases the risk of an OUD, overdose, and death (Schuchat et al., 2017).

The effects of the opioid epidemic are felt across all sociodemographic groups but heavily impact vulnerable populations. Opioid misuse and OUD disproportionately affect U.S. military Veterans, who are more likely than the general population to experience trauma, post-traumatic stress disorder (PTSD), and chronic pain - all factors found to be associated with increased opioid prescription and misuse (U.S. Department of Veterans Affairs, 2018). Pain was 40 percent greater in Veterans than non-Veterans, with significantly higher reported rates of severe pain (Nahin, 2017). Unrelieved and persistent chronic pain contributes to depression, anxiety, poor sleep patterns, decreased quality of life, and substance use disorder. The consequences of chronic pain include lost work productivity, disability, and increased healthcare costs (U.S. Department of Veterans Affairs, 2018). These consequences for non-cancer-related pain constitutes a significant risk factor for OUD in Veterans.

Care for Veterans suffering from opioid addiction is particularly complicated and fragmented. To access care, Veterans and their families must navigate federal systems, state and regional resources (e.g., each state's Department of Veterans Affairs), and community service specialists. Furthermore, the stigma around opioid misuse contributes to a common resistance to seek care and assistance (Wakeman \& Rick, 2018). The interlocking factors of physical injuries, psychological injuries, PTSD, stigma, and unwillingness to seek care are some of the multifaceted contributors to opioid use disorder among Veterans. Traditionally, strategies to control pain and the treatment of trauma have developed within silos (Rosenbaum \& Steel, 2016; Wyldbore \& Aldington, 2013). Various strategies have been utilized to address the opioid crisis. Examples of interventions to improve OUD include increased access to naloxone, increased funding for medication-assisted treatment (MAT), established guidelines for opioid prescribing, increased education of healthcare professionals, and increased public health campaigns (Wickramatilake et al., 2017). However, inadequate infrastructure for MAT delivery and other continued treatment gaps hamper the ability to address the opioid epidemic in the United States (Vashishtha et al., 2017).

\section{Prior Work}

A community-academic partnership launched an opioid misuse prevention project designed to equip Veteran peer support specialists with knowledge to prevent and reduce opioid abuse among military Veterans. This project is referred to as Milwaukee PROMPT: Prevention of Opioid Misuse through Peer Training. Milwaukee PROMPT focused on the prevention of OUD in a subset of the Milwaukee Veteran population by seeking to change their knowledge, attitudes, and behaviors related to opioid misuse.

Prior to the Milwaukee PROMPT project, our Veteran-serving community partner had a formalized peer mentor training program (Franco, et al. 2020; Ruffalo, Hooyer, \& Franco, 2020). This training manual, known as the Dryhootch Quick Reaction Force (QRF) training, consists of 14 modules that provides a set of tools as a general orientation to peer support for military Veterans, covering such topics as (1) peer mentor role, (2) peer mentor responsibilities, (3) peer mentor skills, (4) peer mentor considerations, (5) motivational interviewing, (6) detachment and reintegration, (7) anger management, (8) moral injury, (9) legal issues, (10) dangerous driving, (11) relationship issues, (12) VA benefits, (13) mental health, and (14) health and well-being. The manual did not include detailed information on drug misuse, abuse, or recovery. The community-academic partnership agreed that the best way to address opioid misuse and recovery among Veterans was to create a peer-delivered OUD training manual with a community collaborative 
design strategy. The Milwaukee PROMPT project provided the capacity to develop a second volume of the manual explicitly dedicated to these topics. Training modules would incorporate focus group data, community partner input, and expertise from the academic partners.

This community-engaged research (CEnR) study was based on the belief that a comprehensive, community-engaged prevention and intervention effort is needed to prevent OUD and OUD-related deaths among Veterans. CEnR blends community members as part of the research project team and academic members to work along with community members, creating a unique working and learning environment at all stages of the research project, which requires power-sharing, maintenance of equity, and flexibility in pursuing goals, methods, and time frames (Ahmed \& Palermo, 2010). CEnR seeks to find inclusive solutions to tackle complex community health concerns (Ahmed et al., 2016; Ahmed \& Palermo, 2010; Woolf et al., 2015). The Community Engagement Components Practical Model (Ahmed et al., 2017) includes 5 components: (1) Community Outreach and Service, (2) Education, (3) Clinical Care, (4) Research, and (5) Policy and Advocacy. The Milwaukee PROMPT project intersects 4 of the 5 components: Education of peer mentors, Research of opioid misuse among Veterans, Community outreach with the use of peer trainers to prevent opioid overdose, and Clinical care with access and coaching with mental health services for Veteran peer mentors. Healthcare organizations must organize and utilize community engagement processes to generate meaningful engagement in order to improve population-level health outcomes (Franco et al., 2016).

This paper is organized into 6 sections. First, we provide a history of the community-academic partnership that was leveraged for the Milwaukee PROMPT project. Second, the current community and academic partnership members are described. Third, the collaborative research design used to formulate the OUD peer training manual (Milwaukee PROMPT training curriculum) is detailed, including focus group procedures and the qualitative data analysis approach. Fourth, results including major themes, codes, exemplar quotes, and frequencies of the ideas offered by Veterans, peer mentors, and family and friends of those in recovery, are presented. Fifth, the process of using the findings of the focus group to generate the Milwaukee PROMPT Training is explored. Sixth, the discussion explores limitations, implications, and possible future directions for peer and consumer-driven interventions and training for opioid misuse and recovery.

\section{Community-Academic Partnership History}

The Milwaukee PROMPT effort leveraged a prior 10-year community-academic partnership, the Dryhootch Partnership for Veteran Health (DPVH) (Franco et al., 2016; Franco et al., 2020). The DPVH was a collaboration initiated by a small Veteran-led organization, Dryhootch of America, Inc. (Dryhootch), and faculty at the Medical College of Wisconsin (MCW), the Milwaukee Veterans Affairs (VA) Healthcare System in 2008 (Franco et al., 2014). In 2013, the partnership grew to include faculty at the University of Wisconsin-Milwaukee, Marquette University, and Mental Health America of Wisconsin (MHA) (Franco et al., 2014). DPVH was formed around a mutual interest in making VA services more accessible to all Veterans, as well as a specific emphasis on those returning from overseas deployments in Afghanistan and Iraq, whom they believed were unlikely to seek mental healthcare (Franco et al., 2016).

The DPVH emphasized traditional community based participatory research (CBPR) (Israel et al., 1998) strategies, spending significant time in collaborative discussions, research question formulation with Veterans as subject matter experts, and focused on frequent standing meetings with all partnership members to foster trust and encourage power-sharing within the partnership. Over the course of the partnership, as in all genuine multistakeholder collaborations, many points of friction and celebration occurred (Israel et al., 2017). Over a decade long process, both the Veteran leadership at Dryhootch and the faculty and staff involved from the academic institutions developed much more nuanced understandings of each other's cultures, incentives, and barriers to participating in this type of coalition, and several long-term friendships also emerged as the work of the partnership became part of the daily lives of the members. (For details on the formation of the partnership, see Franco et al., 2016; Franco et al., 2020.) 
Key outcomes from the DHPV included several grants, community co-authored academic articles and a series of Warrior Summit conferences that emphasized the inclusion of the lived experience of Veterans as well as academic scholarship (Franco et al., 2020). Central to this work, the DPVH produced a training manual for peer mentors (Goswami et al., 2021), completed research on the use of mobile technology to support peer mentorship (Franco et al., 2016), and produced a special issue of the Journal of Humanistic Psychology on Veteran collaborative research (Franco et al., 2020).

One of the key principles of CBPR is that genuine partnerships continue to work together and deliver programming even when the partnership is not funded, while also focusing on sustainability (Israel et al., 2017; Schulz et al., 2002). At the end of a large Advancing a Healthier Wisconsin (AHW) grant, the original academic partners felt that they needed to pause, finalize deliverables and publications, and not immediately seek additional funding. However, as a small social services agency, Dryhootch was under continual sustainability pressure. To manage the competing interests of the partners at that juncture, and our desire to further institutionalize Veteran community engagement at an institutional level, a relationship between the partnership at the MCW campus-level community engagement mission office was facilitated. In part because of the duration and maturity of the DPVH (partnership), we were able to transition to focus less on PTSD and Veteran reintegration, pivoting to address the opioid crisis.

This transition in the partnership also marked a shift from traditional CBPR processes to a less processintensive CEnR approach (Ahmed \& Palermo, 2010). While relationship and capacity building remained an important priority for this project, it relied heavily on established social relationships between prior partners to rapidly navigate complexities and also focused on more rapidly pushing to complete research and programmatic tasks (Michener et al., 2012; Ahmed et al., 2015). The project team met regularly to discuss ideas and develop a proposal that was funded by the Robert Wood Johnson Foundation Clinical Scholars Program to address the wicked problem of opioid misuse among Veterans. The Milwaukee PROMPT project offers an important example of how existing community-academic partnerships can serve as platforms for increasingly complex interventions and research as the partnership matures and evolves.

\section{Milwaukee PROMPT Community Partners}

Dryhootch is a nonprofit organization founded in Milwaukee, Wisconsin, in 2008 by a Vietnam Veteran with a mission of helping Veterans and their families. The agency provides peer-to-peer mentoring, recovery programs, and informal social support for Veterans. The format Dryhootch offers are coffee shops that serve as community rally points to provide a welcoming, drug- and alcohol-free environment for Veterans, families, and community members. Dryhootch believes that Veteran peer mentoring is the leading factor during a Veteran's recovery from OUD. The peer mentoring approach includes sharing a lived experience to relate to and understand a peer mentee. The peer mentor can accomplish this by validating a peer mentee's perspective, displaying active listening, being vulnerable about their own experiences, and cultivating trust. This unique relationship built through shared experiences moves Veterans toward recovery.

MHA, one of the original members of the Dryhootch Partnership, was involved in the Milwaukee PROMPT project because of their specific expertise in providing substance abuse and recovery-related peer mentor services as well as a range of clinical services identified as necessary to this project. MHA is an affiliate of the national nonprofit dedicated to helping all Americans achieve wellness by living mentally healthier lives. They have experience operating programs for populations affected by opioid addiction by being the first organization in Milwaukee to have peer mentors and have observed that trauma is almost universal among the people they serve.

\section{Milwaukee PROMPT Academic Partners}

MCW served as the academic partner on the Milwaukee PROMPT project. The Office of Community Engagement led the academic team and utilized readily available CEnR expertise in working through barriers that exist in engaging the community collaboratively (Ahmed \& Palermo, 2010; Ahmed et al., 2016; Ahmed et al., 2017; Franco et al., 2016; Ahmed et al., 2015; Eder et al., 2018; Wilkins \& Alberti, 
2019). The combined expertise and experience of this multidisciplinary academic team positioned us well to collaborate on this project. This expertise included a family physician with extensive experience in CEnR and more than 30 years of practice; a clinical psychologist with expertise in the impact of trauma and trauma-informed care; an anesthesiologist with expertise in the management of chronic pain; a licenseeligible psychologist with expertise in Veteran health issues; and a clinical pharmacist with expertise in pharmacology of opioids and management of chronic pain.

\section{Research Design}

The Milwaukee PROMPT project was a multiphase project with the goal of demonstrating the importance of a CEnR approach with a long-standing community-academic partnership. This CEnR project encouraged partner collaboration (Eder et al., 2013; Nabatchi, 2012) during all phases of the project, including decision making and the design of the project. Furthermore, the project contributed to community empowerment (Eder et al., 2013; Nabatchi, 2012) by cocreating a sustainable program owned and implemented by the community partner, Dryhootch. Keys to Milwaukee PROMPT were the recognition of the community as a source of valuable insights and the promotion of colearning among partners. The project team was intentionally composed of academic and community representatives, including clinicians, researchers, Veterans, and community partner representatives engaged in local work to address Veterans' health issues. The community partners have been essential collaborators through all phases of this project. The Veteran partners completed training in human subjects research and were engaged in the development of the research protocol submitted to the Medical College of Wisconsin Institutional Review Board (IRB).

The project team met twice a month to strengthen engagement, plan project goals, obtain useful insights from the Veteran partners, and make joint decisions about the direction and outcomes of the project. This level and frequency of involvement was especially important to harness the expertise of Veterans with lived experience with OUD. The project team's capacity was enhanced by learning about the lived experience and the perspectives of Veteran stakeholders. Each project team member brought a unique perspective and expertise that built on the strengths and resources found within the community. This paper highlights the phases of the project that involved focus groups, input sessions, and the development of a peer-delivered curriculum.

\section{Collaborative Design of Focus Groups}

The project team collaborated to codesign focus group questions to gather qualitative data for a deeper understanding of the impact of OUD on the Veteran community in order to inform the development of a curriculum that incorporated input from the focus groups with Veterans, peer mentors, and family members and friends who supported Veterans.

\section{Peer Group Recruitment and Composition}

Focus group participants were recruited using print and electronic flyers, and by word-of-mouth via Dryhootch peer mentor specialists. The recruitment flyer, which was codesigned by MCW, Dryhootch, and MHA project staff, instructed interested parties to contact the project partner, MHA, by phone or email to receive more information and to sign up to participate in a focus group if they met eligibility criteria for one of the three target groups. Project partners determined that Dryhootch, a community-based setting, would be an appropriate location for the focus groups. With direction from Veteran partners, these sessions were intentionally designed to provide an intimate conversational setting.

Community members participated in three audience-specific focus groups, targeting three groups: (1) peer mentor specialists who worked with substance abuse populations; (2) Veterans who experienced opioid addiction; (3) family members/friends who supported such Veterans. Each session included both academic and community project team members who served as cofacilitators (two per session), a notetaker, and a licensed counselor observer. Three separate focus groups took place on three different dates to hear the perspectives of Veterans $(\mathrm{N}=5)$, peer mentors $(\mathrm{N}=8)$, and family/friends $(\mathrm{N}=5)$. Focus group members 
were intentionally separated so that each group's thoughts and opinions could be clearly voiced and were not potentially diluted by perspectives of a different group.

\section{Trauma-Informed Safety Protocol}

The protocol to conduct the focus group research with human subjects was approved by the IRB at MCW. There was potential for psychosocial risks due to discussion of OUD and its association with trauma that could result in feelings of sadness, anger, or other negative feelings. Veterans exposed to trauma may engage in different types of risky behavior such as impulsivity and aggression (Hossain et al., 2019). As a precautionary measure, the project team, including academic and community experts in mental health and crisis intervention, created an internal emergency response protocol. The emergency protocol was developed to identify early warning signs displayed by Veterans and the response action that should be taken. The protocol was in place during the focus groups and was later used for the facilitation training of peer mentor specialists. Licensed mental health counseling staff from MHA were on site during each focus group to serve as a resource if anyone needed individual support during the session. Table 1 outlines the Milwaukee PROMPT Emergency Response Protocol.

Table 1

Milwaukee PROMPT Emergency Response Protocol

\begin{tabular}{|c|c|c|}
\hline $\begin{array}{l}\text { Mental Health } \\
\text { Category }\end{array}$ & Early Warning Signs & Response Action \\
\hline Normal & $\begin{array}{ll}\text { - } & \text { Calm } \\
\text { - } & \text { Attentive }\end{array}$ & $\mathrm{N} / \mathrm{A}$ \\
\hline Elevated & $\begin{array}{l}\text { - } \quad \text { Rapid breathing } \\
\text { - } \text { Clenching fists } \\
\text { - } \text { Grinding teeth } \\
\text { - Feeling hot or flushed }\end{array}$ & $\begin{array}{l}\text { - Redirect conversation } \\
\text { - Refocus on a different topic/object } \\
\text { - Prompt person to use coping skills }\end{array}$ \\
\hline $\begin{array}{l}\text { Escalated } \\
\text { (Alert Stage 1) }\end{array}$ & $\begin{array}{ll}\text { - } & \text { Negative talk } \\
\text { - } & \text { Fidgeting } \\
\text { - } & \text { Yelling } \\
\text { - } & \text { Throwing object(s) } \\
\text { - } & \text { Storming out of the room }\end{array}$ & $\begin{array}{l}\text { - Validate feelings } \\
\text { - } \text { Offer to take a break/step outside } \\
\text { - } \text { leaves outside with Veteran if he/she } \\
\text { - Offer post-session debrief or follow-up }\end{array}$ \\
\hline $\begin{array}{l}\text { Exacerbated } \\
\text { (Alert Stage 2) }\end{array}$ & $\begin{array}{ll}\text { - } & \text { Negative talk } \\
\text { - } & \text { Yelling } \\
\text { - } & \text { Pacing } \\
\text { - } & \text { Throwing object(s) }\end{array}$ & $\begin{array}{l}\text { - Validate feelings } \\
\text { - Offer to take a break/step outside } \\
\text { - } \quad \text { Inquire about person's supports } \\
\text { - Schedule appointment with therapist }\end{array}$ \\
\hline $\begin{array}{l}\text { Emergent } \\
\text { (Seek Emergency } \\
\text { Care) }\end{array}$ & $\begin{array}{ll}\text { - } & \text { Panicked } \\
\text { - } & \text { Aggressive }\end{array}$ & $\begin{array}{l}\text { - Inquire about person's supports } \\
\text { - Schedule emergency appointment with } \\
\text { therapist } \\
\text { - Seek nearby assistance } \\
\text { - Call crisis line }\end{array}$ \\
\hline $\begin{array}{l}\text { Crisis } \\
\text { (Imminent Danger) }\end{array}$ & $\begin{array}{ll}\text { - } & \text { Belligerent } \\
\text { - } & \text { Combative } \\
\text { - } & \text { Violent }\end{array}$ & $\begin{array}{l}\text { - } \quad \text { Exit the room and get to safety } \\
\text { - } \quad \text { Call family and/or support person } \\
\text { - } \quad \text { Call } 911\end{array}$ \\
\hline
\end{tabular}




\section{Guiding Questions}

Guiding questions to facilitate the focus group conversations were created with direct participation and expertise of the community partners to make them culturally appropriate and relevant to the focus group target population. Key concepts were identified by the project team, including clinicians, researchers, Veterans, and community partner representatives, as significant discussion points. Key concepts were determined before the focus groups began. The guiding questions and key concepts are outlined in Table 2, Table 3, and Table 4.

\section{Table 2}

Family and Friends of Veterans in Recovery: Target Audience During Focus Group

\begin{tabular}{ll}
\hline Guiding Questions & Key Concepts
\end{tabular}

1. What knowledge has been the most helpful for you to have to support recovery from opioid abuse and addiction? Or, another way to think about it might be: what would you have liked to have known about supporting Veterans with addiction problems when you were just starting out in your role as a peer mentor?

- Knowledge

- Support recovery
2. What skills or techniques have been the most helpful to facilitate recovery from opioid abuse and addiction?

3. Imagine a training module for peer mentors designed to help build additional skills to assist Veterans in opioid recovery. What training topics would enhance your skill set for this work?
- Skills or techniques

- Facilitate recovery

- Training topics

- Skill set for this work

4. What resources do you need to support your work as a peer mentor/peer mentor specialist?

- Resources

5. What do professionals need to know about preventing opioid abuse and addiction?

- Prevention

6. What skills and techniques do you use now that you might not have when you first started in your role as a peer mentor?

a. What strategies do peer mentors use to support recovery that may differ from clinicians' strategies?

b. How do you address denial if you feel a Veteran isn't honest with you or themselves about things like a relapse?

c. How do you build trust with a Veteran who has a substance abuse history?

- Strategies

d. Do you address trauma's role in addiction with the Veterans you work with? If so, what has been the most effective way to explain how trauma and addiction are sometimes related

e. How do you address accountability with Veterans in recovery for things like sobriety or keeping agreements they've made with you? 
Table 3

Veterans: Target Audience during Focus Group

\section{Guiding Questions}

What knowledge do you now have that you wish you would have known prior to abusing opioids?

What have you learned during your recovery journey that would be useful to another person/Veteran in recovery?

What interventions (from family members, friends, or professionals) do you think would be most helpful in facilitating recovery from opioid abuse or addiction?

What knowledge would be most helpful to enable/empower/equip a Veteran to end their opioid abuse or addiction?

What skills or techniques would be most helpful to enable/empower/equip a Veteran to end their opioid abuse or addiction?

What might motivate another person/Veteran in recovery to end their opioid abuse or addiction?

\section{Key Concepts}

- Personal experience

- Knowledge during recovery

- Interventions

- Facilitating recovery

- Equip

- Technique

- Motivation

Table 4

Peer Mentors: Target Audience During Focus Group

\section{Guiding Questions}

What knowledge do you now have that you wish you would have known prior to supporting a Veteran family member/friend struggling with opioid addiction and abuse?

What emotional, physical or other supports did you provide that you feel contributed to successful recovery?

What resources would be useful to you in your role supporting a Veteran during the recovery journey? What resources do you wish you had at the beginning of the journey?

What knowledge or information would be useful to you in your role supporting a Veteran during recovery? What knowledge or information do you wish you had at the beginning of the journey?

What skills or techniques have been/would be useful to you in your role supporting a Veteran during recovery? What knowledge or information do you wish you had at the beginning of the journey?

What have you personally learned as a result of supporting a Veteran during recovery?

\section{Key Concepts}

- Knowledge

- Support

- Successful recovery

- Resources

- Retrospective Information

- Skills

- Techniques

- Personally learned 
The guiding questions did not focus on individual behaviors so as to reduce the likelihood of participants disclosing potentially incriminating or personally damaging information. The following strategies were used to manage risks: (1) guiding questions were constructed to not ask for such disclosures by taking a case-based approach; (2) discussions were guided in a manner that minimized disclosure of such information; (3) facilitators discussed with participants at the beginning of the focus group sessions that we were not looking for such personal disclosures, but rather thoughts and ideas related to strategies that might be effective in OUD prevention; and (4) facilitators redirected focus group discussion when participants started making personal disclosures.

\section{Content Analysis}

An audio-recording device was used to capture ideas expressed during the focus group sessions. Focus group content was transcribed by Midwest Transcription Services, LLC. The project team reviewed and coded text comments by reading the full transcripts. Thematic content analysis (Joffe \& Yardley, 2004) was conducted through manual coding of the qualitative data. The data were coded using open-coding strategies drawn from grounded theory (Glaser \& Strauss, 1967; Cutcliffe, 2000) as a systematic way to gradually identify themes from the concepts discussed in the focus groups. Two MCW project staff separately reviewed, took notes, and coded the transcript line by line to reconcile themes and collaboratively work toward coder agreement. Possible meanings, associations, and nuances were noted and then reviewed with Veterans as a method of member checking (Birt et al., 2016). Each theme was ranked in numerical order by the highest frequency of codes to the lowest frequency of codes to assist in showing which ideas seemed most salient for the groups. However, low frequency themes and codes also contribute important information, and we have attempted to retain meanings by showing all codes and how they were grouped into themes.

\section{Results}

The information provided in focus groups allowed for nuanced perspectives that fostered a deeper appreciation of the knowledge and service gaps within the Veteran population by using a CEnR approach. A total of 19 themes emerged from the focus groups. Examples of the themes include (1) relational skills, (2) emotional pain and avoidance, (3) inadequate care system, (4) selfcare and wellness, (5) warning signs and relapse prevention, (6) the impact of trauma, (7) root or underlying issues of drug use, and (8) physical pain. All overarching themes across the three focus groups are shown in Figure 1.

The theme of relational attributes was most frequently mentioned during all three focus groups. Relational attributes were linked to codes around compassion, trust, honesty, and active listening. The next most frequently mentioned themes were emotional pain and avoidance and inadequate care system. Further context of direct quotes and codes that emerged within each theme are shown in Table 5.

\section{Milwaukee PROMPT Curriculum Development}

The project team reviewed the identified themes that emerged from the content analysis. Over an 8-week period during the summer of 2018, the academic program coordinator hosted multiple input sessions to discuss focus group data codes and emergent themes on topics such as trauma and relational attributes. Input sessions were a space for consultation, feedback, and added contextual interpretation of the data from PROMPT community partners. Additionally, the community partners expressed that peer mentors working with Veterans would benefit from professional support and clinical education to ensure selfcare and prevent relapse. 


\section{Figure 1}

Themes That Emerged From Code Frequencies During Focus Groups

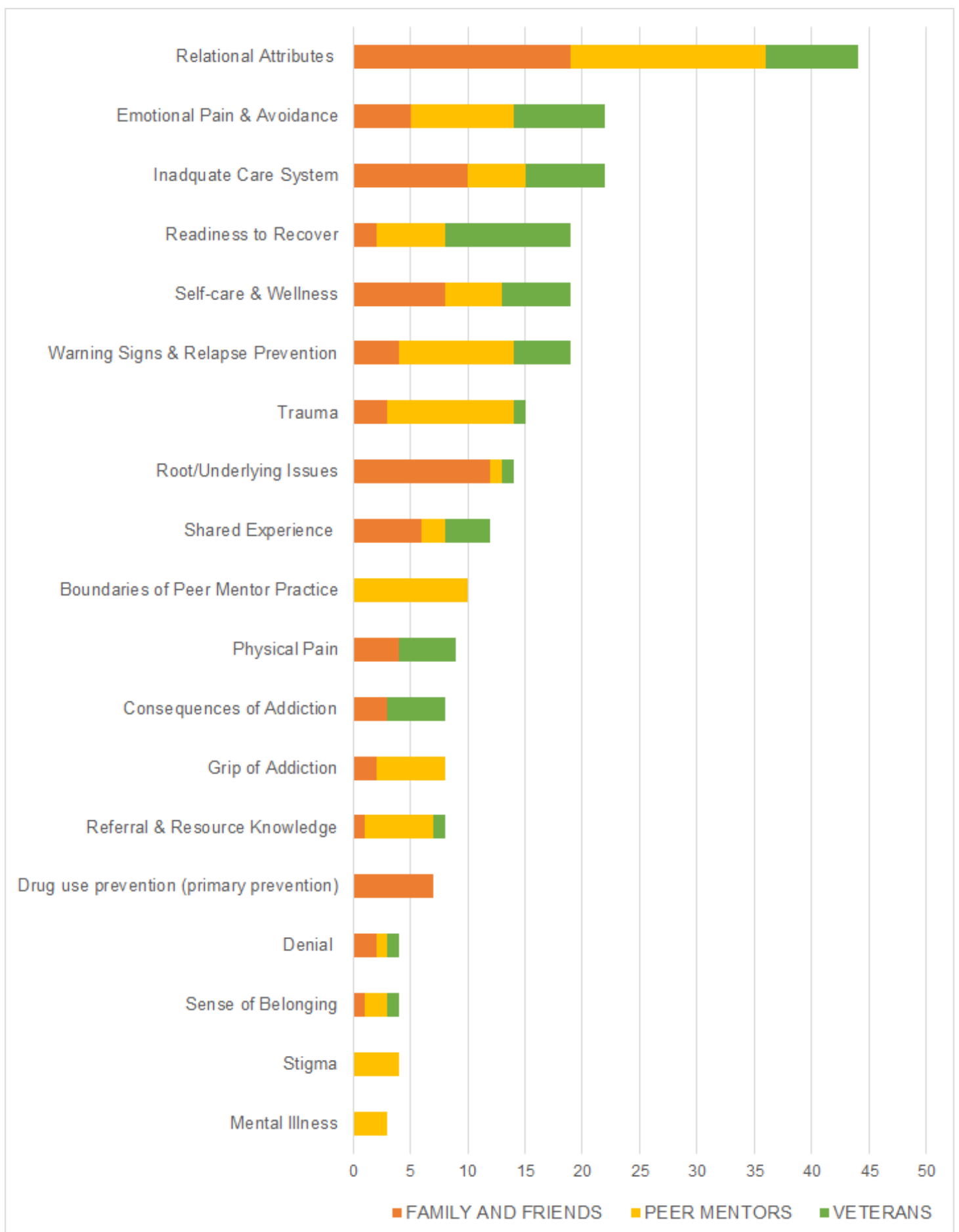


Table 5

Themes, Coding Context, and Frequencies

\begin{tabular}{|c|c|c|}
\hline Themes & Exemplar Quote and Codes & Frequency \\
\hline $\begin{array}{l}\text { Relational } \\
\text { Attributes }\end{array}$ & $\begin{array}{l}\text { "It's a long road back. One of the things that I find very helpful is } \\
\text { first showing acts of sympathy, compassion, love, and support." } \\
\text { - Empathy, compassion } \\
\text { - Accepting, nonjudgmental } \\
\text { - Trust, honesty (can recognize "fakers") } \\
\text { - Identifying needs through active listening } \\
\text { - Neutral agenda/allows peer to maintain autonomy }\end{array}$ & 44 \\
\hline $\begin{array}{l}\text { Emotional Pain } \\
\text { and Avoidance }\end{array}$ & $\begin{array}{l}\text { "I would go to the drugs and whatever drug that would be, you } \\
\text { know, to alleviate that emotional burden that I'm carrying around } \\
\text { because I haven't let it out yet. I haven't processed it." } \\
\text { - Avoiding/not facing/dealing with difficult emotions } \\
\text { - Using substance to avoid feelings and/or escape reality }\end{array}$ & 22 \\
\hline $\begin{array}{l}\text { Inadequate Care } \\
\text { System }\end{array}$ & $\begin{array}{l}\text { "Here's the things where the doctors got to hold the other doctors } \\
\text { accountable because a lot of them doctors, they're just, they're drug } \\
\text { dealers." } \\
\text { - Rehab locations near community areas known for drug use } \\
\text { - Physician knowledge or awareness on the realities of } \\
\text { addiction } \\
\text { - Prescribing practices }\end{array}$ & 22 \\
\hline $\begin{array}{l}\text { Selfcare and } \\
\text { Wellness }\end{array}$ & $\begin{array}{l}\text { "So that's my thing is I try to find something positive or give some } \\
\text { hope or something. You're not gonna do it if you do the same exact } \\
\text { things and live in the same environment. So, my thing is, you gotta } \\
\text { change what you're doing, find some passion for something and if } \\
\text { you do that you got a shot." } \\
\text { - Encouragement to learn and love yourself; one who values } \\
\text { himself does not destroy himself } \\
\text { - Development of a self-value } \\
\text { - Engaging in activities that promote and build self-esteem } \\
\text { - Finding one's passion and purpose as a means of addressing } \\
\text { hopelessness, addressing despair, and seeing hope }\end{array}$ & 19 \\
\hline $\begin{array}{l}\text { Warning Signs } \\
\text { and Relapse } \\
\text { Prevention }\end{array}$ & $\begin{array}{l}\text { "And a good peer mentor would see the relapse coming because } \\
\text { hopefully they've bonded to that point, the relationship has grown to } \\
\text { that point where they talk often and see each." } \\
\text { - Warning signs of potential/impending relapse } \\
\text { - Be observant; watch for inconsistency between words and } \\
\text { actions; warning signs often spread out over several, varying } \\
\text { time points } \\
\text { - Knowing yourself/knowing ways to continue to maintenance } \\
\text { your sobriety e.g., therapy, support groups, connect with } \\
\text { sponsor, etc. } \\
\text { - Avoiding people or environments that may cause relapse }\end{array}$ & 19 \\
\hline $\begin{array}{l}\text { Readiness to } \\
\text { Recover }\end{array}$ & $\begin{array}{l}\text { "I went through } 6 \text { treatments and all of them except the last I wasn't } \\
\text { trying to hear what they were talking about." } \\
\text { - Acknowledge that individuals determine their readiness to } \\
\text { recover or quit } \\
\text { - Windows of readiness vary from person to person }\end{array}$ & 19 \\
\hline
\end{tabular}




\begin{tabular}{|c|c|c|}
\hline Themes & Exemplar Quote and Codes & Frequency \\
\hline Trauma & $\begin{array}{l}\text { "I saw people kill themselves by infection by fecal matter because } \\
\text { they lost their genitals, or they lost } 1 \text { head wound. People } \\
\text { were all messed up and they didn't want to live with their face blown } \\
\text { off." } \\
\text { - Traumatic experience: abuse, injury, natural disaster, death, } \\
\text { loss of loved one } \\
\text { - Unresolved trauma/unaddressed trauma } \\
\text { - Difficulty talking about trauma } \\
\text { - Implication that substance misuse is linked to past trauma }\end{array}$ & 15 \\
\hline $\begin{array}{l}\text { Root/ } \\
\text { Underlying } \\
\text { Issues }\end{array}$ & $\begin{array}{l}\text { "So, the addiction runs deeper than the very using of the substance." } \\
\text { - Coming from a family with substance abuse issues } \\
\text { - Having an addictive personality } \\
\text { - Underlying despair, unresolved emotions } \\
\text { Environment where friends and relatives regularly abuse } \\
\text { drugs }\end{array}$ & 14 \\
\hline $\begin{array}{l}\text { Shared } \\
\text { Experience }\end{array}$ & $\begin{array}{l}\text { "I think that I learned the consequences better when it was told to me } \\
\text { by someone that looks like me, talks like me, walk like me, you } \\
\text { know, my cultural background, you know." } \\
\text { - Feeling understood by someone who has a shared } \\
\text { experience } \\
\text { - Having the ability to influence someone's behavior when } \\
\text { they share similar experiences e.g., are also a Veteran, have } \\
\text { also used drugs, have also been homeless, etc. }\end{array}$ & 12 \\
\hline $\begin{array}{l}\text { Boundaries of } \\
\text { Peer Mentor } \\
\text { Practice }\end{array}$ & $\begin{array}{l}\text { "Boundaries are huge 'cause I think as recovery folks ourselves, we } \\
\text { didn't have boundaries for so long and establishing those boundaries } \\
\text { is very critical and it takes a lot of effort." } \\
\text { - Healthy boundaries between peer mentor and peer, making a } \\
\text { distinction between peer mentor and friend } \\
\text { - Considering personal triggers to maintain boundaries }\end{array}$ & 10 \\
\hline Physical Pain & $\begin{array}{l}\text { "My right hip was blown off. I laid on a mountain for five days } \\
\text { before they could get me out of there. Got a horrible infection and I } \\
\text { ended up in a body cast for almost a year and in the initial part of } \\
\text { once they got me to the hospital and started giving me morphine. I } \\
\text { became really addicted to morphine within three weeks." } \\
\text { - Military-related wounds, injuries, and surgery due to combat } \\
\text { - Extreme physical pain; pain that prevents daily life activities }\end{array}$ & 9 \\
\hline $\begin{array}{l}\text { Consequences } \\
\text { of Addiction }\end{array}$ & $\begin{array}{l}\text { "I wish I would've known how much the, how counterproductive } \\
\text { these things can be, how much they can destroy a family." } \\
\text { - Recognized that addiction robbed time, relationships, } \\
\text { experiences, money, financial security/stability } \\
\text { - Missing out on life's enjoyable experiences } \\
\text { - Serving jail time }\end{array}$ & 8 \\
\hline $\begin{array}{l}\text { Grip of } \\
\text { Addiction }\end{array}$ & $\begin{array}{l}\text { "Opioids is one thing that's pretty hard to stop to do. It physically } \\
\text { kind of just draws you in all the time." } \\
\text { - Strong, physical, and emotional attachment to the substance } \\
\text { - Comparing the need for drugs as the need for water } \\
\text { - Human relationships replaced with substance }\end{array}$ & 8 \\
\hline
\end{tabular}




\begin{tabular}{|c|c|c|}
\hline Themes & Exemplar Quote and Codes & Frequency \\
\hline $\begin{array}{l}\text { Referral and } \\
\text { Resource } \\
\text { Knowledge }\end{array}$ & $\begin{array}{l}\text { - "So, one of the successes is being available and then actually } \\
\text { the opportunity to have resources being available to them } \\
\text { and I'm not just talking about the clinical side or, to apply } \\
\text { for all the resources that are there." } \\
\text { - Knowledge of clinical connections; connecting the mentee } \\
\text { to a trusted clinician } \\
\text { - Knowledge of community resources }\end{array}$ & 8 \\
\hline $\begin{array}{l}\text { Drug Use } \\
\text { Prevention } \\
\text { (Primary } \\
\text { prevention) }\end{array}$ & $\begin{array}{l}\text { "So even a scared straight kind of approach with somebody who's } \\
\text { kind of on the road to addiction or something like that maybe by } \\
\text { having conversation with somebody who's been there." } \\
\text { - Videos or "scared straight" tours of correctional facilities; } \\
\text { view of the "devastation" of drug use } \\
\text { - Warnings of the consequences of drugs } \\
\text { - Cautions or lessons from others who have experienced the } \\
\text { misfortune from the path of substance use }\end{array}$ & 7 \\
\hline Denial & $\begin{array}{l}\text { "And the difference I see is that...the successes, they were, they stop } \\
\text { the denial part of their brain and actually realize that they have a } \\
\text { problem and actually started working on it for real." } \\
\text { - Denial of a problem/need/issue to address } \\
\text { - Hiding addiction; wearing a mask }\end{array}$ & 4 \\
\hline $\begin{array}{l}\text { Sense of } \\
\text { Belonging }\end{array}$ & $\begin{array}{l}\text { "You think you're helping them but really you're seeding whatever } \\
\text { they're going for and it's hard because a lot of us Veterans are still } \\
\text { looking for that brotherhood to take care of somebody like that." } \\
\text { - Seeking camaraderie and brotherhood } \\
\text { - Loss of community or loss of camaraderie when leaving the } \\
\text { military }\end{array}$ & 4 \\
\hline Stigma & $\begin{array}{l}\text { "Once an addict, always an addict. That's a myth, but we've heard } \\
\text { that before though." } \\
\text { - Looked down upon in society; seen as "less than" because of } \\
\text { drug use } \\
\text { - Not having the ability to openly talk about the trauma of war }\end{array}$ & 4 \\
\hline Mental Illness & $\begin{array}{l}\text { "Then there's a component of mental health laying on top of that, } \\
\text { you know, that it kind of exacerbates that whole thing." } \\
\text { - Having a diagnosis such as PTSD, depression, bipolar, or } \\
\text { schizophrenia } \\
\text { - Thoughts of suicide }\end{array}$ & 3 \\
\hline
\end{tabular}

\section{Peer Mentor Training}

The project team requested the consent of Veterans, who agreed to participate in the research as peer mentor specialists with lived experiences. Based on the experiential expertise of the community partner, it was determined that four Veterans peer mentors, who were in recovery from OUD, would be trained by the project team. Peer mentors were required to be at least 2 years clean from opioid use prior to the training. Existing Dryhootch personnel recruited the peer mentor specialist based on their regular, in-person interactions with visitors and patrons of Dryhootch locations, programs, and events. After four peer mentor specialists were identified, the QRF training manual was administered. 
After receiving the QRF training, peer mentor specialists were then trained with the newly developed Milwaukee PROMPT curriculum. This training occurred over 3 days in sessions that covered the 6 modules and were cofacilitated by community partners. This curriculum is now being used by the community partner, Dryhootch, to inform a peer-delivered invention among Veterans misusing opioids. The new training manual focused on conveying technically accurate but approachable material on OUD for Veteran peer mentors. The multistep focus group process provided rich qualitative data that assisted the project team in better understanding which types of information were most critical to include.

\section{Discussion}

Characteristics of peer mentoring are associated with trust and rapport and involves self-disclosure, role modeling, and a sense of belonging (Davidson et al., 2012; Pickett et al., 2012). Peer mentoring has been shown to improve outcomes and increase access to treatment in the areas of mental health such as PTSD and substance use recovery (Chinman et al., 2015). In contrast to mental health professionals, peer mentors can more readily disclose aspects of their life as a tool for helping and share their path to recovery (Kleeet al., 2019). Due to their shared experiences, peer mentors have success in promoting recovery, fostering resilience, and building on patients' strengths to support community integration (Klee et al., 2019). Growing evidence exists about the positive impact of peer mentoring for Veterans obtaining access to mental health services (Chinman et al., 2015, Resniket al., 2017). Peer mentoring services may be a more impactful approach because Veterans may feel more comfortable discussing their military experiences with those who share the same background and because this approach does not have the stigma associated with seeking professional mental health care (Resnick \& Rosenheck, 2008).

Trauma continues to be an area of focus for Veterans, peer mentors, and family/friends. Military Veterans are more likely than the general population to experience trauma, chronic pain, and PTSD, all of which are associated with opioid use. To highlight these interlocking factors, it has been shown that PTSD and chronic pain among Veterans are highly correlated (Shipherd et al., 2007; U.S. Department of Veterans Affairs, 2018). A study found that 532 Veterans who died from an intentional overdose while receiving care from the VA received prescriptions for opioids for noncancer chronic pain in 2004 and 2005 (U.S. Department of Veterans Affairs, 2018). Evidence indicates that exposure to abuse, neglect, discrimination, violence, and other adverse experiences increases an individual's lifelong potential for serious health problems and engaging in health-risk behaviors (SAMHSA, 2014). Trauma-informed care models and approaches have been shown to improve general well-being, decrease stress, strengthen beliefs, and assist individuals who have experienced trauma, PTSD, or substance misuse to attain a sense of safety (SAMHSA, 2014).

This study extends our understanding of how to better intervene with Veterans who are struggling with OUD and how to prevent other Veterans from OUD-related deaths through collaboratively designed OUD peer mentor training. Trauma, emotion avoidance, and root causes of addiction were key themes, reinforcing the importance of a trauma-informed lens when working with Veterans and peer mentors.

\section{Implications}

Peer mentor services are recognized as a healthcare provision by all states and within healthcare systems, including the VA (Nelson et al., 2019); however, peer mentor specialist training varies from state to state. Certified peer mentor specialists are recognized in Wisconsin after completing training, examination, and the continuing education requirements specific to both mental health and substance use. In Wisconsin, peer mentor specialists are required to complete 48 hours of training but currently are not required to complete specific training related to working with military Veterans. CEnR remains a mainstay of reaching military Veteran populations. A CEnR framework emphasized community stakeholder input throughout the research project, from concept development to reporting of results. Veterans' perspectives were central to the research process in this project. We foresee the potential of the concepts derived from this project being used for other Veteran communities outside Milwaukee, Wisconsin. Additionally, future work will describe 
how our community partner, Dryhootch, has built capacity by adapting the Milwaukee PROMPT curriculum for use in its standard peer mentor training, which it provided locally and statewide.

The CEnR framework used in this project may offer nuanced information for community-academic partnership projects that use a collaborative process to tackle complex community health concerns such as OUD. The targeted population for this project were Veterans experiencing OUD; however, we foresee that this framework could eventually serve as a model for engaging with other communities and at-risk populations.

\section{Limitations}

As focus groups were only allotted 2.5 hours of time per group session, there was insufficient time to cover all the guided questions, which may have affected the themes that emerged. There are inherent differences in the dynamics of the facilitators' interactions with group members in a focus group. Also, individual factors such as temperament, personality traits, age, and gender may influence the nuances in the content. One way we sought to mitigate this limitation was that project team members met prior to the focus groups and established a semi-structured process that included co-designing guiding questions with significant concepts that needed to be discussed. Furthermore, additional post-focus group meetings that took place allowed for further discussion on topics that later influenced the development of the PROMPT curriculum. The measures used in this study may lack external validity. There is also an acknowledgment that the content may not capture widely differing views due to a small number of participants, demographics, and lived experiences of members of the focus groups. The variables in this case may or may not affect the degree of generalizability. However, this is a problem inherent in qualitative research, and our results may still provide valuable insight for Veterans experiencing OUD.

Lastly, due to the small scope of research on peer mentorship and the lack of research on the intersection of Veterans with OUD and peer mentorship, a longitudinal mixed-methods study is needed to determine whether the findings described above remain stable over time. This project had three separate focus groups for whom the questions used were not the same and provided different perspectives about what was important. Therefore, the relative frequency of codes and themes by group may inherently be different. Additionally, we did not analyze the differences of the groups beyond showing the frequencies. The findings from this study contribute to the limited body of literature focused on Veterans with OUD and the impact of peer mentoring.

\section{Conclusion}

This project addressed a wicked problem in our community by using a CEnR approach that positioned the community and academic project team members as equal and collaborative partners in the research design. Employing CEnR principles during the focus groups, input sessions, and curriculum development was the first step toward a comprehensive, community-engaged prevention effort to advance understanding of how peer mentors can support Veterans with OUD. The themes that emerged from the focus groups and analysis resulted in a peer-delivered training curriculum with key concepts related to opioid misuse and recovery. Engaging Veterans and community organizations throughout the Milwaukee PROMPT project provided a robust framework to impact Veterans struggling with OUD. It also allowed for nuanced perspectives that fostered a deeper appreciation of the knowledge and service gaps within the Veteran population.

We envision that the next set of similar research could expand to seek further input from a wider pool of Veterans who have experienced OUD and the people who support them. Questions could dig deeper into the themes identified in this study's focus groups to further elucidate important concepts for support and recovery from OUD. We also envision that the methodology could be replicated to determine ways that peer mentors can support other populations struggling with OUD or Veterans experiencing other health issues. 


\section{References}

Ahmed, S. M., Maurana, C., Nelson, D., Meister, T., Young, S. N., \& Lucey, P. (2016). Opening the black box: Conceptualizing community engagement from 109 community-academic partnership programs. Progress in Community Health Partnerships: Research, Education, and Action, 10(1), 51-61. http://doi.org/10.1353/cpr.2016.0019

Ahmed, S. M., Nelson, D., Kissack, A., Franco, Z., Whittle, J., Kotchen, T., Meurer J. R., Morzinski, J. Brandenburg, T. (2015). Towards building a bridge between community engagement in research (CEnR) and comparative effectiveness research (CER). Clinical and Translational Science, $8(2)$, 160-165. https://doi.org/10.1111/cts.12236

Ahmed, S. M., Neu Young, S., DeFino, M. C., Franco, Z., \& Nelson, D. A. (2017). Towards a practical model for community engagement: Advancing the art and science in academic health centers. Journal of Clinical and Translational Science, 1(5), 310-315. https://doi.org/10.1017/cts.2017.304

Ahmed, S. M., \& Palermo, A.-G. S. (2010). Community engagement in research: Frameworks for education and peer review. American Journal of Public Health, 100(8), 1380-1387. https://doi.org/10.2105/ajph.2009.178137

Birt, L., Scott, S., Cavers, D., Campbell, C., \& Walter, F. (2016). Member checking. Qualitative Health Research, 26(13), 1802-1811. https://doi.org/10.1177/1049732316654870

Chinman, M., Oberman, R. S., Hanusa, B. H., Cohen, A. N., Salyers, M. P., Twamley, E. W., \& Young, A. S. (2015). A cluster randomized trial of adding peer specialists to intensive case management teams in the Veterans health administration. The Journal of Behavioral Health Services \& Research, 42(1): 109-121. https://doi.org/10.1007/s11414-013-9343-1

Cutcliffe, J. R.. (2000). Methodological issues in grounded theory. Journal of Advanced Nursing, 31(6), 1476-1484. https://doi.org/10.1046/j.1365-2648.2000.01430.x

Davidson, L., Bellamy, C., Guy, K., \& Miller, R. (2012). Peer support among persons with severe mental illnesses: A review of evidence and experience. World Psychiatry, 11(2), 123-128. https://doi.org/10.1016/j.wpsyc.2012.05.009

Eder, M., Carter-Edwards, L., Hurd, T. C., Rumala, B. B., \& Wallerstein, N. (2013). A logic model for community engagement within the Clinical and Translational Science Awards consortium. Academic Medicine, 88(10), 1430-1436. https://doi.org/10.1097/acm.0b013e31829b54ae

Eder, M., Evans, E., Funes, M., Hong, H., Reuter, K., Ahmed, S., Calhoun, K., Corbie-Smith, G., Dave, G., DeFino, M., Harwood, E., Kissack, A., Kleinman, L. C., \& Wallerstein, N. (2018).

Defining and measuring community engagement and community-engaged research: Clinical and translational science institutional practices. Progress in Community Health Partnerships: Research, Education, and Action, 12(2), 145-156. https://doi.org/10.1353/cpr.2018.0034

Franco, Z. E., Flower, M., Whittle, J., \& Sandy, M. (2014) Professional ethics and virtue ethics in community-engaged healthcare training. In D. Mitchell \& R. Ream (Eds.), Professional responsibility. advances in medical education (Vol. 4, pp. 221-229). Springer.

Franco, Z. E., Logan, C., Flower, M., Curry, B., Ruffalo, L., Brazauskas, R., \& Whittle, J. (2016). Community Veterans' decision to use V.A. services: A multimethod Veteran health partnership study. Progress in Community Health Partnerships: Research, Education, and Action, 10, 5-5. https://doi.org/10.1353/cpr.2016.0000 
Franco, Z., Hooyer, K., Ruffalo, L., Ho-Fung, R. A. (2020). Foreword to special issue on Veterans health and well-being - Collaborative research approaches: Toward Veteran community engagement. Journal of Humanistic Psychology, 61(3), 287-312. https://doi.org/10.1177/0022167820919268

Glaser, B. G., \& Strauss, A. L. (1967). The discovery of grounded theory: Strategies for qualitative research. Cambridge University Press.

Goswami, A., Franco, Z., Berte, K., Curry, B., Gollin-Graves, M., Hoyer, K., Flower, M., Ahamed, S., Ruffalo, L., Stoffel, V., Winstead, O., \& Whittle, J. (2021). Evaluating the Dryhootch partnership for Veteran health: Implications for local, regional and national Veteran community engagement [Manuscript submitted for publication]. Department of Family and Community Medicine, Medical College of Wisconsin.

Hossain, F., Olawunmi, G., \& Johnson, N., Madiraju, P., Flower, M., Franco, Z., Hooyer, K., Mazaba, J., Rein, L., \& Ahamed, S. (2019, July 15-19). Towards clinical decision support for Veteran mental health crisis events using tree algorithm. 2019 IEEE 43rd Annual Computer Software and Applications Conference (COMPSAC) [Conference session]., Milwaukee, WI, United States

Israel, B. A., Schulz, A. J., Parker, E. A., \& Becker, A. B. (1998). Review of community-based research: Assessing partnership approaches to improve public health. Annual Review of Public Health, 19(1), 173-202. https://doi.org/10.1146/annurev.publhealth.19.1.173

Israel, B. A., Schulz, A. J., Parker, E. A., Becker, A. B., Allen, A. J., Guzman, J. R., \& Lichtenstein, R. (2017). Critical issues in developing and following CBPR principles. In M. Minkler \& N. Wallerstein (Eds.), Community-based participatory research for health: Advancing social and health equity (pp. 32-35). Jossey-Bass.

Joffe, H., \& Yardley, L. (2004). Content and thematic analysis. In D. F. Marks \& L. Yardley (Eds.), Research methods for clinical and health psychology (pp. 56-68). SAGE.

Klee, A., Chinman, M., \& Kearney, L. (2019). Peer specialist services: New frontiers and new roles. Psychological Services, 16(3), 353-359. http://dx.doi.org/10.1037/ser0000332

Mattson, C. L., Tanz, L. J., Quinn, K., Kariisa, M., Patel, P., \& Davis, N. L. (2021). Trends and geographic patterns in drug and synthetic opioid overdose deaths - United States, 2013-2019. Morbidity and Mortality Weekly Report, 70(6), 202-207. https://doi.org/10.15585/mmwr.mm7006a4

Michener, L., Cook, J., Ahmed, S. M., Yonas, M. A., Coyne-Beasley, T., \& Aguilar-Gaxiola, S. (2012). Aligning the goals of community-engaged research. Academic Medicine, 87(3), 285-291. https://doi.org/10.1097/acm.0b013e3182441680

Milwaukee Community Opioid Prevention Effort. (2019). Milwaukee County opioid-related overdose report. https://city.milwaukee.gov/ImageLibrary/Groups/healthAuthors/SAPrevention/Opioids/PDF/MilwaukeeCountyOpioid-RelatedOverdoseReport_v6_Final.pdf

Nabatchi, T. (2012). Putting the "public" back in public values research: Designing participation to identify and respond to values. Public Administration Review, 72(5), 699-708. https://doi.org/10.1111/j.1540-6210.2012.02544.x

Nahin, R. L. (2017). Severe pain in Veterans: The effect of age and sex, and comparisons with the general population. The Journal of Pain, 18(3), 247-254. https://doi.org/10.1016/j.jpain.2016.10.021

Nelson, C. B., Lusk, R., Cawood, C., Boore, L., Ranganathan, A., \& Lyubkin, M. (2019). Predictors of CBT-pretreatment intervention engagement and completion: Evidence for peer support. Psychological Services, 16(3), 381-387. https://doi.org/10.1037/ser0000268 
Pickett, S. A., Diehl, S. M., Steigman, P. J., Prater, J. D., Fox, A., Shipley, P., Grey, D. D. \& Cook, J. A. (2012). Consumer empowerment and self-advocacy outcomes in a randomized study of peer-led education. Community Mental Health Journal, 48(4), 420-430. https://doi.org/10.1007/s10597$\underline{012-9507-0}$

Resnick, S. G., \& Rosenheck, R. A. (2008). Integrating peer-provided services: A quasi-experimental study of recovery orientation, confidence, and empowerment. Psychiatric Services, 59(11), 13071314. https://doi.org/10.1176/ps.2008.59.11.1307

Resnik, L., Ekerholm, S., Johnson, E. E., Ellison, M. L., \& O'Toole, T. P. (2017). Which homeless Veterans benefit from a peer mentor and how? Journal of Clinical Psychology, 73(9), 1027-1047. https://doi.org/10.1002/jclp.22407

Rosenbaum, S., \& Steel, Z. (2016). Breaking down the silos of treatment for post-traumatic stress disorder: Integrating mind and body. The Medical Journal of Australia, 204. https://doi.org/10.5694/mja15.01165

Ruffalo, L., Hooyer, K., \& Franco, Z. (2020) Incorporating Veteran voices in a peer mentor training: Developing the quick reaction force program. Journal of Humanistic Psychology. Advance online publication. https://journals.sagepub.com

SAMHSA. (2014). SAMHSA's concept of trauma and guidance for a trauma-informed approach. http://store.samhsa.gov/shin/content/SMA144884/SMA14-4884.pdf

Schuchat, A., Houry, D., \& Guy, G. P., Jr (2017). New data on opioid use and prescribing in the United States. JAMA, 318(5), 425-426. https://doi.org/10.1001/jama.2017.8913

Schulz, A. J., Parker, E. A., Israel, B. A., Allen, A., Decarlo, M., \& Lockett, M. (2002). Addressing social determinants of health through community-based participatory research: The East Side Village Health Worker Partnership. Health Education \& Behavior, 29(3), 326-341. https://doi.org/10.1177/109019810202900305

Shipherd, J. C., Keyes, M., Jovanovic, T., Ready, D. J., Baltzell, D., Worley, V., Gordon-Brown, V., Hayslett, C., \& Duncan, E. (2007). Veterans seeking treatment for post-traumatic stress disorder: What about comorbid chronic pain? Journal of rehabilitation research and development, 44, 153-165. https://doi.org/10.1682/JRRD.2006.06.0065

U.S. Department of Veterans Affairs. (2018). Office of Research \& Development: V.A. research on pain management. Retrieved March 2, 2020, from https://www.research.va.gov/topics/pain.cfm

Vashishtha, D., Mittal, M. L., \& Werb, D. (2017). The North American opioid epidemic:

Current challenges and a call for treatment as prevention. Harm Reduction Journal, 14(1), Article 7. https://doi.org/10.1186/s12954-017-0135-4

Visconti, A. J., Santos, G.-M., Lemos, N. P., Burke, C., \& Coffin, P. O. (2015). Opioid overdose deaths in the city and county of San Francisco: Prevalence, distribution, and disparities. Journal of Urban Health, 92(4), 758-772. https://doi.org/10.1007/s11524-015-9967-y

Wakeman, S. E., \& Rich, J. D. (2018). Barriers to medications for addiction treatment: How stigma kills. Substance Use \& Misuse, 53(2), 330-333. https://doi.org/10.1080/10826084.2017.1363238

Wickramatilake, S., Zur, J., Mulvaney-Day, N., Klimo, M. C. von, Selmi, E., \& Harwood, H. (2017). How states are tackling the opioid crisis. Public Health Reports, 132(2), 171-179. https://doi.org/10.1177/0033354916688206

Wilkins, C. H., \& Alberti, P. M. (2019). Shifting academic health centers from a culture of community service to community engagement and integration. Academic Medicine, 94(6), 763-767. https://doi.org/10.1097/acm.0000000000002711 
Woolf, S. H., Purnell, J. Q., Simon, S. M., Zimmerman, E. B., Camberos, G. J., Haley, A., \& Fields, R. P. (2015). Translating evidence into population health improvement: Strategies and barriers. Annual Review of Public Health, 36, 463-482. https://doi.org/10.1146/annurev-publhealth-082214110901

Wyldbore, M., \& Aldington, D. (2013). Trauma pain - A military perspective. British Journal of Pain, 7(2), 74-78. https://doi.org/10.1177/2049463713487515.

\begin{abstract}
Author Note
Support for this project was provided by Clinical Scholars, a national leadership program supported by the Robert Wood Johnson Foundation. The Milwaukee PROMPT Clinical Scholars team is composed of Syed M. Ahmed, M.D., MPH, DrPH; Kajua B. Lor, PharmD, BCACP; and L. Kevin Hamberger, Ph.D., all from the Medical College of Wisconsin; and Robert Hurley, M.D., Ph.D., from Wake Forest University.

After discussing the use of the word Veteran with our community partner and checking the Department of Veterans Affairs Style Guide, we capitalized the word Veteran.
\end{abstract}

\begin{abstract}
About the Authors
Myah Pazdera, M.S., is the Milwaukee PROMPT program coordinator in the Office of Community Engagement at the Medical College of Wisconsin.
\end{abstract}

Kajua B. Lor, PharmD, BCACP, is an associate professor and the chair of the Department of Clinical Sciences in the School of Pharmacy at the Medical College of Wisconsin.

Otis Winstead Jr. is the Executive Director at Dryhootch of America, Inc.

L. Kevin Hamberger, Ph.D., is a professor emeritus in the Department of Family and Community Medicine at the Medical College of Wisconsin.

Bob Curry is the founder and president of Dryhootch of America, Inc.

Zeno Franco, Ph.D., is an associate professor in the Department of Family and Community Medicine at the Medical College of Wisconsin.

Sarah O'Connor, M.S., is a program manager in the Office of Community Engagement at the Medical College of Wisconsin.

Martina Gollin-Graves, MSW, is the president and CEO at Mental Health America of Wisconsin.

Robert Hurley, M.D., Ph.D., is associate dean for the Office of Faculty Development and a professor in the Department of Anesthesiology at Wake Forest University.

Tiffiney Gray, M.S., M.A., was the Milwaukee PROMPT program coordinator in the Office of Community Engagement at the Medical College of Wisconsin.

Syed M. Ahmed, M.D., MPH, DrPH, is the former Inaugural Associate Provost inaugural associate provost and senior associate dean for community engagement and a professor emeritus in the Department of Family and Community Medicine at the Medical College of Wisconsin.

Correspondence concerning this article should be addressed to communityengagement@mcw.edu 